\title{
The Virtual 3D Representation of Old Railroad and Street of Jingtong
}

\author{
Naai-Jung Shih and Chin-Lin Lin
}

\begin{abstract}
The purpose of this study is to represent the old Railroad and street culture of Jingtong, Taiwan. The study is conducted from an urban scale to a building level, including street facade, open space, and human behavior. 3D scan data have been collected and carefully integrated for the most effective illustration of local cultures. This study extended the size and the complexity of 3D scan to an urban environment by using a Faro Focus 3D ${ }^{\circledR}$ laser scanner. Experiencing an old street and railroad through the 3D scanned data of urban fabric has led to the creation of a new fabric definition in terms of building enclosures and flexible part of fabric. The scan data can be used as the most updated digital reference for urban fabric study. A new application paradigm of 3D scan data is proofed to be useful in illustrating a small town's activity which is closely related to daily life.
\end{abstract}

Keywords—urban fabric, 3D scan, as-built data, old streets

\section{Background}

This research is to record urban fabric under a municipal scale based on the experience of tourist's route. This is part of a two-year study effort in scanning urban environments, which are closely related to people's daily living experiences. The scans were conducted at a small town in New Taipei City, Taiwan, including streets, railroad, and open spaces. In order to comprehend the local culture, the connection between urban scale and shop scale has to be established. The urban fabrics, as a summation of urban artifact configuration, usually feature consistent appearance and structure for years under a space framework that can achieve, and interpret the cross-relationship and identity between buildings and street $[5,7,10]$. The representation of urban fabrics requires as-built data to verify the relationship between space and tourist's behavior. In order to capture realistic data from streets, the concept of virtual cities [2] should be promoted to include as-built city data to reflect the real content of an environment. Virtual 3D city models are becoming more widely implemented by governments and city planning services $[9,13]$; this requires highly detailed $3 \mathrm{D}$ models that reflect the complexity of city objects and their interrelations.

Naai-Jung Shih

National Taiwan University of Science and Technology Taiwan

Chin-Lin Lin

National Taiwan University of Science and Technology Taiwan

The data from all platforms need to be exchangeable for the best description of an environment [1,11]. Traditional $2 \mathrm{D}$ drawings are no longer sufficient. The technical- and policy-related barriers must be excluded from the institutional points of view [8], so the data cross different ownership can be retrieved. Nowadays, city modeling has reached a new standard in which $3 \mathrm{D}$ point cloud models have been treated with rich geometric properties and rich details, which enable the clouds to be integrated with other city model types [12]. Since the cloud models are as-built data, the integration with old environmental data leads to a specific application in showing the most current status of the environment or in contrasting the changes.

Traditional 2D drawings or 3D Digital Terrain Models (DTM) are used for the fundamental reference of spatial structures. To think outside the rigid spatial-temporal framework, scan models should be taken and should be used to illustrate the development of urban models. GIS technology is very helpful in the cognition and interpretation of the urban fabric status [14]. Now Unmanned Aerial Vehicles (UAVs) or aerial LIDAR (Light Detection and Ranging) can add a more detailed description of as-built geometric information [3] with different levels of accuracy. The vast amount of data actually opens up opportunities in various fields of study [11], especially when showing the complexity of city objects and their interrelations [6].

\section{Research Purpose}

The purpose of this research is to record urban fabric of Jingtong, New Taipei City, under a municipal scale. From the viewpoint of architectural details, the study is conducted from an urban scale to a building level, including street facade, open space, railroad, to local culture activities. The 3D scan data have been collected and carefully integrated for the most effective illustration of local cultures. Experiencing a route through the 3D scanned data of urban fabric leads to the creation of a new fabric definition in terms of combining building enclosures and flexible part of signage or urban furniture. Both the scan and photogrammetry data can be applied as the most updated digital reference for urban 3D study. A new application paradigm of 3D scan data is proofed to be useful in illustrating urban activity which is close-related to open space. The physical objects and user activity has been created as a connection between virtual world and real world.

This study explores the cultural and urban fabric of Jingtong old streets with the major works as:

- Scan and illustration of the old street fabrics (Fig. 1);

- Investigation of the street commercial activity and culture aspects;

- Present the potential conflicts between the residential area and the commercial activities;

- Scan of spaces and buildings around railroad (Fig. 2). 


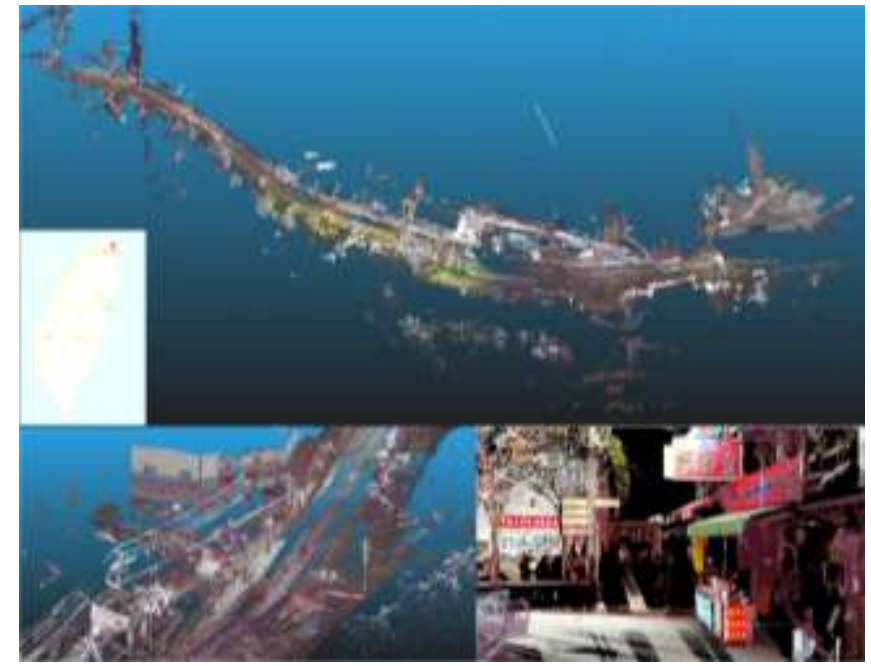

Figure 1. Point cloud of Jingtong scan-based map (top) and the scenes around railroad and old street (bottom)

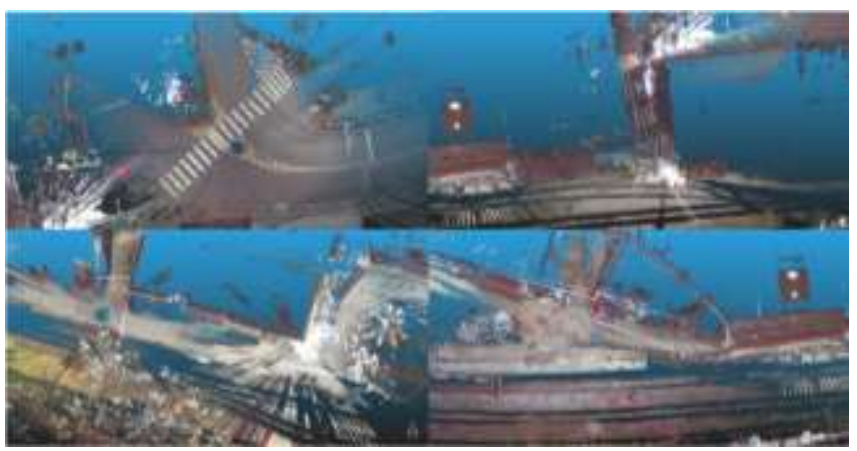

Figure 2. The top views from the street entrance to train station

\section{Methods}

People recognize a space with different emphasis. Virtual data are usually applied to illustrate subject which is closely related to how people is usually perceived. By focusing the as-built environment, a 3D scanner is used to capture spatial data that associated with local culture. The advantage is to identify a space or a location at the first sight, and the data are precise enough for measurements in a 1:1 scale.

This study extended the size and the complexity of 3D scan to an urban environment by using a Faro Focus $3 \mathrm{D}^{\circledR}$ laser scanner. With a range of $80-120 \mathrm{~m}$, a street about 500 meter long was retrieve. The result is a set of cloud models of about 50 million points. To view the model, other than by the scanner's host platform, the data was exported under different resolutions to Meshlab ${ }^{\circledR}$, CloudCompare ${ }^{\circledR}$, and Geomagic Studio ${ }^{\circledR}$ for registration and visualization purpose.

\section{Iv. The Presentation of Old Street and Railroad}

The point-cloud-based urban scene can be seen in Fig. 3 . The scene is a combination of hill, railroad, trains, shops, residences, and people. Associated urban fixtures include electrical poles, wires, wall advertisements, etc.

All the scans have been registered into a large point cloud model. In order to relate as-built artifacts to landscape, a series sections are made along the main east-west axis. The section is cut from scan data by dividing it into 5 zones as from A to E (Fig. 4). The results show a number of types of boundary and adjacency next to railroad, from a highly enclosed corridor near the street entrance to an open space between residences and hill. Among which, temporary installations like canopies and panels are applied by local shops to define their shop front and to shape the major street scene of Jingtong.

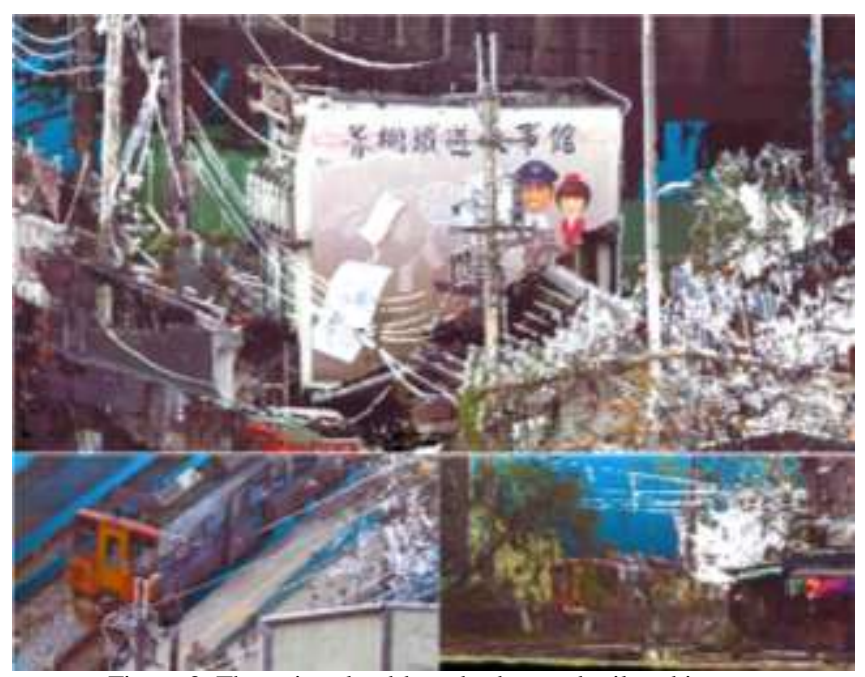

Figure 3. The point-cloud-based urban and railroad images
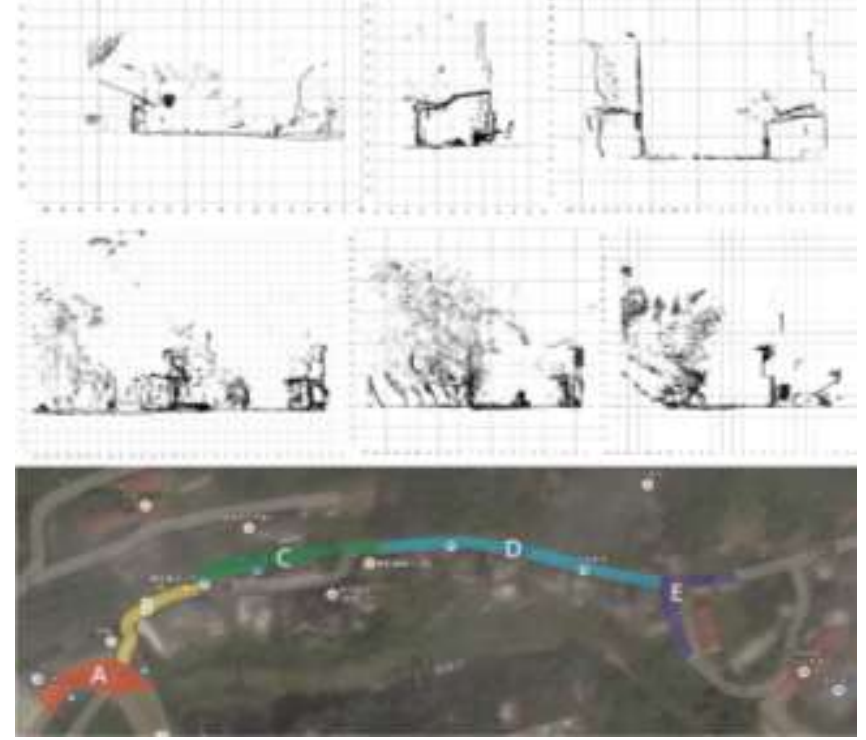

Figure 4. The point-cloud-based sections of major space

Walking environment in a commercial area is very important for pedestrians, as the related issues include basic functions, maintenance quality, visual aesthetics, number of activities, etc. The invisible linear space of traversal can be created without clearly defined boundary. In Jingtong, the street width is related to the connection of activities. The railroad, the sense of enclosure, and the shops like local Lantern booths (Fig. 5) have created specific local street scene. The old street is parallel to the railroad, and it appears most of the tourist activities are gathered around the railroad. 

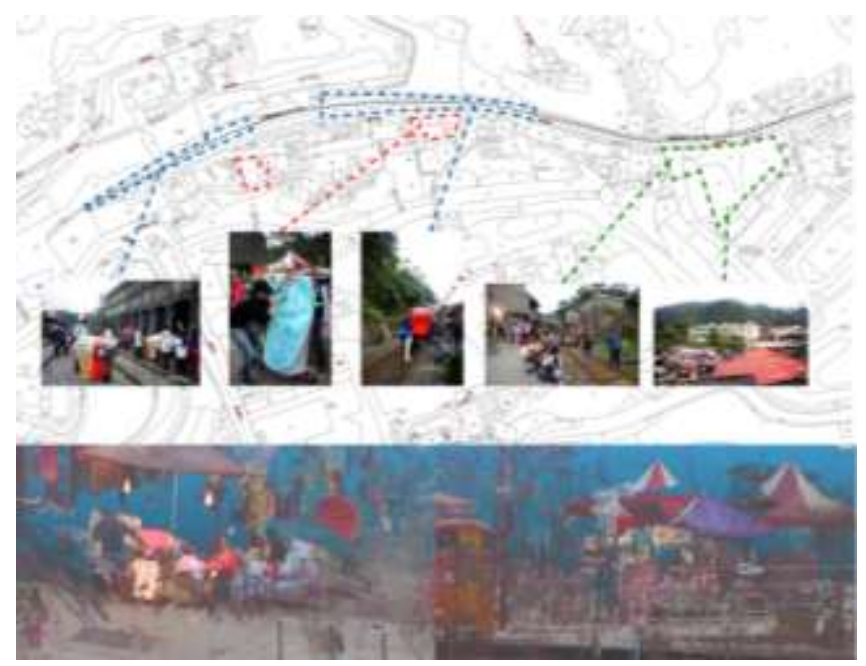

Figure 5. Lantern booths and the point cloud representation

\section{v. Culture Activities and the Railroad}

The legend of bamboo tube came from an old love story of a local couple. This story has been circulated for a long time as a Jingtong-specific romantic memory [4]. In order to memorize and promote the legend, local community and commercial society hosted an activity in Valentine's Day, 2008 , by providing free bamboo tube as a gift. Since then, the tubes appear in various locations and created a special urban scene (Fig. 6).

The locations of tube cluster generated a specific signature of local urban fabric, which is also changing. Comparing to 2012 Google Street Scene, no advertisement panels were installed for shops near railroad. Only very small number of bamboo tubes was hung on the fence next to the railroad in early days. The number increases significantly between 2012 and 2015. To be noticed, the location of tube shack was relocated after railroad platform remodeling.

As stated in previous section, the railroad acts like a local cultural icon that most of the tourist activities are circled around it. Taking the wishing tube for example, the shops selling tubes and the locations hanging them are gathered next to the railroad. Tubes are hang on fences between sidewalk and railroad, cross the shops. After the space are full, the site is moved to a tree cross the railroad. The result is a tree with tubes hang all over its branches (Fig. 6). Since this tree is just located cross the train station, it looks like a welcome sign to the people arrive by train.

The interaction between local icon and wish-projection behavior leads the small town being evolving to a scalable setting. It seems tourists have created a new behavior pattern by assigning specific meaning to the space near old street and railroad. Not only the shops or booths deploy accordingly to meet the population of tourists, but the landscape and open space are used for wish-making like hanging tubes and flying lanterns. Although warning sign is installed, taking pictures with the railroad has become part of the visit.

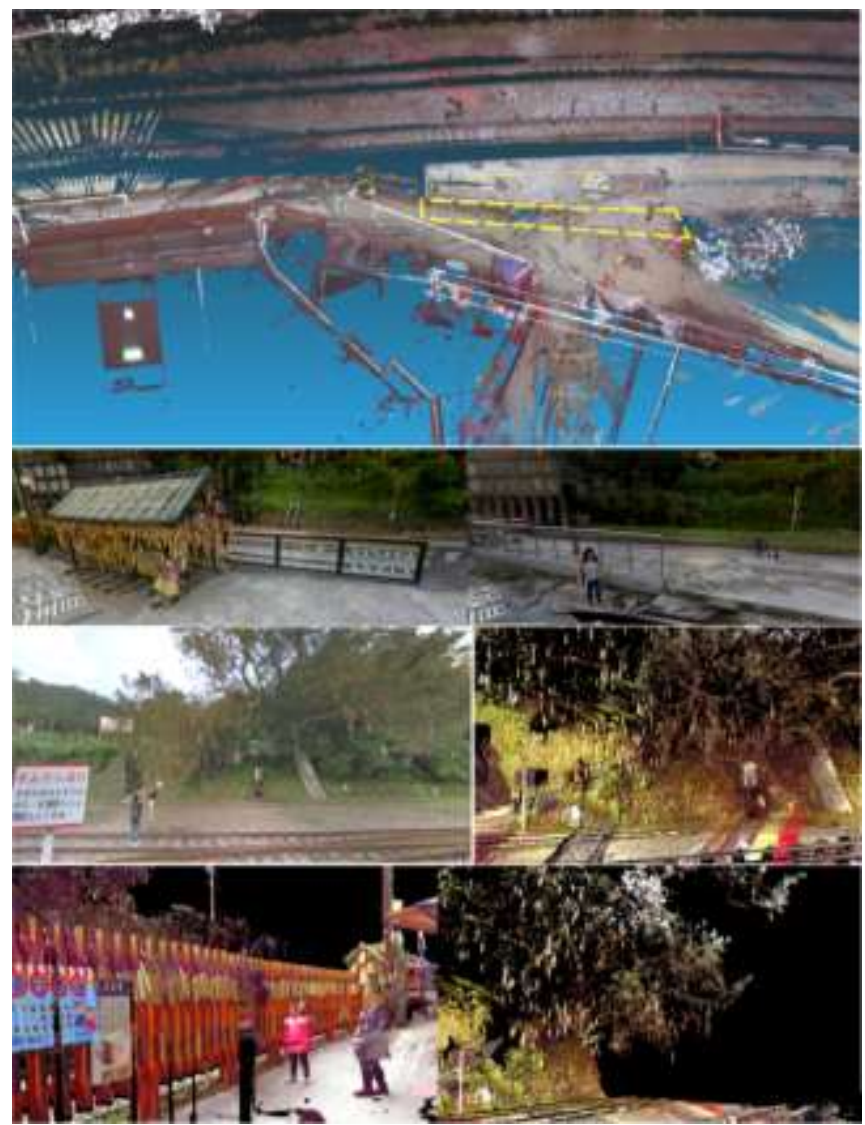

Figure 6. The reallocation of bamboo tubes in 2012 and 2015 (top), referred by scan data, and the hanging bamboo tubes on fence and trees (bottom)

\section{vi. Conclusion}

Experiencing old streets and railroad through the 3D scanned data of urban fabric has led to the creation of a new fabric definition in terms of building enclosures and cultural part of fabric. The scan data can be used as the most updated digital reference for urban fabric study. To support a study from an urban scale to a detail level, the data were collected and carefully integrated for the most effective illustration of subject. Most important of all, a new application paradigm of 3D scan data is proofed to be useful in illustrating urban activity which is closely related to tourist's experience, not just the 2D drawings or GIS data. The connection between virtual world and real world has never been closer.

\section{Acknowledgment}

This research is sponsored by the Ministry of Science and Technology of Taiwan, ROC. The involved project number is MOST 105-2221-E-011 -014 -MY2. The author expresses sincere appreciation.

\section{References}

[1] Bishop, D., Escobar, F. J., Karuppannan, S., Suwarnarat, K., Williamson, I. P., Yates, P. M., Yaqub, H. W., Spatial Data Infrastructures for Cities in Developing Countries - Lessons from the Bangkok Experience, Cities, 17(2), 85-96, 2000.

[2] Chen, B., Huang, F., Fang, Y., Integrating virtual environment and GIS for 3D virtual city development and urban planning, International Geoscience and Remote Sensing Symposium 2011, Vancouver, Canada, 4200-4203, 2011.

[3] Czyńska, K., Application of LIDRA data and 3D-city models in visual 
impact simulations of tall buildings, The International Archives of the Photogrammetry, Remote Sensing and Spatial Information Sciences, Volume XL-7/W3, 2015, 36th International Symposium on Remote Sensing of Environment, Berlin, Germany, 11-15, 2015.

[4] Department of Information and Tourism, Characteristic business streets - street themes,

http://www.taipeitravel.net:8080/frontsite/tw/tips/store Li stAction.do? method $=$ doStoreList \&menuId $=2010203 \&$ filte $r=$ false \& type Id $=62$, Taipei City Government, 2015.

[5] Hull, R. B., Lamb, M., and Vigo, G., Place identity: symbols of self in the urban fabric, Landscape and Urban Planning, 28, pp.109-I 20, 1994

[6] Nebiker, S.; Bleisch, S.; Christen, M, Rich Point Clouds in Virtual Globes - A New Paradigm in City Modeling? Computers, Environment and Urban Systems, 34, 508-517, 2010.

[7] Nüchter, A., Gutev, S., Borrmann, D., Elseberg, J., Skyline-based registration of 3D laser scans, Geo-spatial Information Science, 14(2), 85-90, 2011.

[8] Rajabifard, A.; Williamson, I.; Kalantari, M., Ed., A National Infrastructure for Managing Land Information - Research Snapshot, The University of Melbourne, Centre for Spatial Infrastructures and Land Administration, Department of Infrastructure Engineering, 2012.

[9] Sadek, E.S.S.B., Ali, S. J. B. S. and Kadzim, M. R.B.Md., The Design and Development of a Virtual 3D City Model http://www.hitl.washington.edu/people/bdc/virtualcities.pdf, 2015.

[10] Shih, N.J., Lee, C.Y., Jhan, S.W., Wang, G.S., Jhao, Y.F., Digital Preservation of a Taiwanese Historical Settlement: Using 3D postconstruction scan to develop an application framework and reference for Beipu Township, Cities, 28, 193-205, 2011.

[11] Shih, N.J., Tzen, S.C., Chan, T.Y., Lee, C.Y., Cross-Verification of As-Built Point Cloud and GIS-Related Map Data, Open Journal of Civil Engineering, 3, 219-227, 2013.

[12] Shojaei, D., Chapter 9: 3D Visualisation as a Tool to Facilitate Managing Land and Properties, In: A. Rajabifard, I. Williamson and M. Kalantari, Ed., A National Infrastructure for Managing Land Information - Research Snapshot, The University of Melbourne, Centre for Spatial Infrastructures and Land Administration, Department of Infrastructure Engineering, 88-94, 2012.

[13] Stadler, R., Kolbe, T.H., Spatio-semanti Coherence in the Integration of 3D City Models, Commission II, WG II/7, 2013.

[14] Xiang, H. and Ye, H., Research on the Urban Fabric of Wuhan based on GIS and MAS. IGARSS 3, 1232-1235, 2008.

About Author (s):

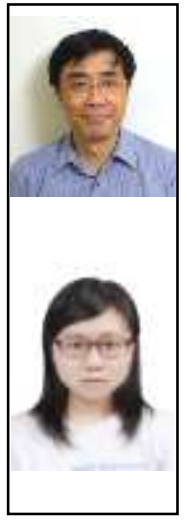

Naai-Jung Shih:

professor,

Department of Architecture

National Taiwan University of Science

and Technology

Chin-Lin Lin:

$1^{\text {st }}$ year master student,

Department of Architecture

National Taiwan University of Science and Technology 